\title{
Flexural behaviour of hybrid sandwich panel with natural fiber composites as the intermediate layer
}

\author{
J. Fajrin ${ }^{*}$, Y. Zhuge ${ }^{2}$, F. Bullen ${ }^{2}$ and H. Wang ${ }^{2}$ \\ ${ }^{1}$ Department of Civil Engineering, Faculty of Engineering, University of Mataram, \\ Mataram, NTB, Indonesia, 83125 \\ *Email: jauhar.fajrin@unram.ac.id \\ Phone: +62370638436; Mobile Phone: +62 81237883527 \\ ${ }^{2}$ School of Civil Engineering and Surveying, University of Southern Queensland, \\ Toowoomba, QLD, Australia, 4350
}

\begin{abstract}
Polymeric composites reinforced with natural fibers have raised more attention as the alternative building materials. In this work, natural fiber composites prepared from jute and hemp fiber were proposed for the intermediate layer of a hybrid sandwich panel. This paper presented the flexural behavior of the newly developed hybrid sandwich panel which included the comparison of the ultimate load, load-deflection behavior, load-strain behavior and failure modes. The study was designed as a single factor experiment where the performance of hybrid sandwich panels containing jute fiber composite (JFC) and hemp fiber composite (HFC) as the intermediate layer was compared to the control (CTR) which was a conventional sandwich panel without an intermediate layer. A static flexural test under a four-point bending load scheme was performed in accordance with the ASTM C 393-00 standard. Aluminium sheet was used as the skins, while expanded polystyrene (EPS) was employed for the core. The testing was performed using a $100 \mathrm{kN}$ servohydraulic machine with a loading rate of $5 \mathrm{~mm} / \mathrm{min}$. The applied load, displacement and strains were obtained using data logger. The results demonstrated that the hybrid sandwich panel exhibited a more superior performance than the conventional sandwich panels. The intermediate layer contributed significantly to enhancing the load carrying capacity of the hybrid sandwich panel. The load carrying capacity of hybrid panel with the JFC intermediate layer was $29.60 \%$ higher than the conventional sandwich panel, and correspondingly $93.46 \%$ higher for the sandwich panel with the HFC intermediate layer. The hybrid sandwich panels also developed a much larger area under the load-deflection curve, indicating greater toughness. The introduction of intermediate layer helped the hybrid sandwich panels to sustain a larger strain prior to reach their ultimate loads, resulting in a higher deformation capability. Indentation and core shear were observed as the failure mode of the conventional sandwich panel. Meanwhile, core shear and delamination were identified as the failure mode of the hybrid sandwich panel.
\end{abstract}

Keywords: Natural fibre composites; sandwich panel; hybrid; flexural behavior.

\section{INTRODUCTION}

The conventional form of sandwich structure consists of two face layers separated by a core material. The faces usually consist of thin and high performing material, such as composite laminates made from carbon or glass fibres, while the core material is a low density with relatively low performing material which results in highly specific 
mechanical properties of the panel under loadings. The choice of constituent materials depends mainly on the specific application and design criteria of the sandwich panel products [1]. The most outstanding benefit of this type of composite structure is its high strength and stiffness to weight ratio [2-8]. On the other hand, this typical structure also has a few drawbacks; they suffer from strong stress concentration at the interfaces between the face sheets, the weak adhesive layer, and the core, as a consequence of the distinctly different properties of these materials in contact [9]. The layered configuration of the sandwich panel, the considerable differences in the elastic properties between the face-sheets and the core, and the manufacturing process make the panel susceptible to defects in the form of debonding between the face-sheets and the core [4]. A lot of research work has been done on improving the properties of sandwich panel composites [10-24]. The enhancement efforts were done by either improving the skin or core properties or even introducing a new element inside to form a hybrid sandwich structure. The first category is the enhancement of face sheet materials which has been extensively investigated by many researchers [10-15]. The most important attempt is the introduction of fibre composites skin, which has a major impact on the use of sandwich panel composite. Some enhancements in this area have been the development of a glass fibrereinforced polymer face sheets [15] and the introduction of corrugated skins. In the second category, extensive works have been carried out on dealing with the issue of enhancing the properties of core materials. Included in this category is the sandwich panel with irregular arrangement of fibrous core [3], the sandwich panel with Kagome lattice cores reinforced by carbon fibres [16], and also the sandwich panel with a honeycomb core [17-21]. In the third category, a few studies have also been carried out on introducing a new element to improve the properties of composite sandwich panel such as sandwich panel with additional sheets inserted within the core [25], and more recently, insulated concrete sandwich wall panel reinforced with glass fiber reinforced polymer as the shear connector [26]. Furthermore, sandwich panel with intermediate layers inserted between the face sheets and the core developed by Mamalis et al. [27] provided a more practicable choice. The reason for the additional layer is obvious in that it reduces the mismatch between stress levels and material functionality.

The work reported in this paper is actually an extended investigation of the above reported research [27], where natural fiber composite (NFC) laminates prepared from jute and hemp fiber reinforced epoxy resin were proposed for the intermediate layer. One of the current research trends in this field is the application of natural fiber composites for structural application such as a sandwich structure. In a recent study, a sandwich structure composite was developed using bamboo reinforced epoxy [28]. In addition, the feasibility of natural fiber composite material for engineering application has been studied extensively [29]. The main concept proposed in this work was using natural fiber composite laminates as the intermediate layer between aluminium skins and expanded polystyrene core to produce a hybrid composite sandwich panel. This new structure is a combination of two components; composite sandwich panel with aluminium skins and EPS foam core as an integrated sandwich structure and intermediate layer laminates made of NFCs, resulting in a hybrid composite structure. The natural fiber composites employed for the intermediate layer in this work were prepared from epoxy polymer matrix reinforced with jute and hemp fiber. It is worth noting that using thermoset resin such as epoxy and polyester is strongly recommended as the matrix in developing natural fiber composites for structural applications [30]. Research into the feasibility of reinforcing epoxy or polyester with natural fibers has been reported in several literature [31-34]. A comprehensive theoretical framework for the new sandwich structure panel 
developed in this research under flexural loading was thoroughly discussed [35], while the statistical analysis of the flexural test was reported earlier [36]. More recently, a statistical analysis of the in-plane shear behaviour of the newly developed panel was also reported [37]. The aim of this paper was to investigate the structural behaviour of the newly developed hybrid panel under flexural loading which included the comparison of the ultimate load, load-deflection behaviour, load-strain behaviour and failure modes. The paper was also trying to compare the performance of hybrid sandwich panel with the conventional sandwich panel without an intermediate layer.

\section{EXPERIMENTAL SET UP}

\section{Sample Preparations}

Sandwich panel specimens were manually prepared using a pressing system. All constituent parts were cut into the same length and width and glued together using structural grade adhesive and placed in the pressure system. A torque wrench tool was used when tightening up all the bolts to ensure uniform pressure given to the samples. The samples were cut and shaped into a span length of $450 \mathrm{~mm}$ and the size of $550 \times 50 \times 22$ $\mathrm{mm}$ for length, width and thickness, respectively. The characteristics of Aluminium skin and EPS core used in this research are presented in Table 1.

Table 1. Properties of skin and core materials.

\begin{tabular}{lcll}
\hline \multicolumn{2}{c}{ Skin: Aluminium } & $5005 \mathrm{H} 34$ & \multicolumn{1}{c}{ Core: Isolite ${ }^{\circledR} \mathrm{EPS}$} \\
\hline Density $(\rho)$ & $: 2700$ & Grade & $:$ VH (Very High) \\
& $\mathrm{kg} / \mathrm{m} 3$ & & $: 28 \mathrm{~kg} / \mathrm{m} 3$ \\
Modulus Elasticity $(\mathrm{E})$ & $: 68.2 \mathrm{GPa}$ & Density $(\rho)$ & $: 7250 \mathrm{kPa}(7.25$ \\
Poisson ratio & $: 0.33$ & Modulus Elasticity & $\mathrm{MPa})$ \\
& & $(\mathrm{E})$ & $: 0.35$ \\
Shear modulus & $: 25.9 \mathrm{GPa}$ & Poisson ratio & $: 337 \mathrm{kPa}$ \\
$\begin{array}{l}\text { Shear strength } \\
\text { Ultimate tensile }\end{array}$ & $: 96.5 \mathrm{MPa}$ & Flexural strength & $: 240 \mathrm{kPa}$ \\
strength & $: 159 \mathrm{MPa}$ & Shear stress & \\
Yield tensile strength & $: 138 \mathrm{MPa}$ & & \\
\hline
\end{tabular}

The skin was made of aluminium 5005 H34 sheet produced by Austral Wright Metals. Aluminium 5005 is a lean aluminium magnesium alloy, and contains nominally $0.8 \%$ magnesium which can be hardened by cold work. It has medium strength, good weldability, and good corrosion resistance. It also has excellent thermal conductivity and low density. An expanded polystyrene (EPS) was used for the core of this hybrid sandwich panel. The commercial name of this EPS core is Isolite ${ }^{\circledR}$, which is a brand name of RMAX block moulded flame retardant modified grade of expanded polystyrene. It is a closed cell, resilient, lightweight rigid cellular plastic material. For the intermediate layer, jute fiber composite (JFC) and hemp fiber composite (HFC) laminates were used with the thickness of $3 \mathrm{~mm}$. The laminates were prepared with jute and hemp fiber reinforced epoxy. The jute fibres (Hessian jute) were available in a continuous roll and seemed like the most readily available natural fibres in the current market. The fibres used in this research were chemically treated prior to further process for NFC laminates fabrication using alkali treatment. A vacuum bagging process was used for preparing the natural fibre laminates, which is a process that combines the manual method of using hand-layup or spray-up on 
the open mould to produce a laminated component followed by a vacuum process after covering the laminates using polymeric sheet. The mechanical properties of the intermediate layers are presented in Table 2. The thickness of EPS core for control level (CTR) was $21 \mathrm{~mm}$ and $15 \mathrm{~mm}$ for the other two levels to maintain a constant overall thickness of $22 \mathrm{~mm}$ for the specimen. As required by the standard, the test specimen shall be rectangular in the cross section. The depth of specimen shall be equal to the thickness of the sandwich construction and the width shall be not less than twice the total thickness. The specimen length shall be equal to the span length plus $50 \mathrm{~mm}$ or plus one half of the sandwich thickness, whichever is the greater. The thickness of skin and core were estimated as recommended by Zenkert [2], where the core/face thickness is commonly in the regime of 10 to 50. The thickness of the EPS core used in this work was approximately 42 times the thickness of the skins. The face/core modulus ratio may also be used for determining the thickness, which is between 50 and 1000 [2]. Each level was replicated 4 times; hence the total of samples tested was 12 samples. The arrangement of the flexural test is shown in Table 3.

Table 2. Properties of intermediate layer.

\begin{tabular}{lll}
\hline Mechanical properties & $\begin{array}{l}\text { Jute fiber composite } \\
\text { (JFC) }\end{array}$ & $\begin{array}{l}\text { Hemp fiber composite } \\
\text { (HFC) }\end{array}$ \\
\hline Modulus Elasticity (E) & $: 4502 \mathrm{MPa}$ & $: 3048 \mathrm{MPa}$ \\
Poisson ratio & $: 0.361$ & $: 0.391$ \\
Tensile strength & $: 42.44 \mathrm{MPa}$ & $: 31.37 \mathrm{MPa}$ \\
Shear strength & $: 27.7 \mathrm{MPa}$ & $: 23,45 \mathrm{MPa}$ \\
Flexural strength & $: 56.23 \mathrm{MPa}$ & $: 51.7 \mathrm{MPa}$ \\
Compressive strength & $: 57.26 \mathrm{MPa}$ & $: 31.69 \mathrm{MPa}$ \\
\hline
\end{tabular}

Table 3. Experimental arrangements for flexural testing.

\begin{tabular}{cccccccc}
\hline \multirow{2}{*}{$\begin{array}{c}\text { Samples } \\
\text { Code }\end{array}$} & Material & $\begin{array}{c}\text { Thickness } \\
(\mathrm{mm})\end{array}$ & Material & $\begin{array}{c}\text { Thickness } \\
(\mathrm{mm})\end{array}$ & Material & $\begin{array}{c}\text { Thickness } \\
(\mathrm{mm})\end{array}$ & $\begin{array}{c}\text { Number } \\
\text { of } \\
\text { sample }\end{array}$ \\
\cline { 2 - 6 } CTR & Aluminium & 0.5 & None & None & EPS & 21 & 4 \\
JFC & Aluminium & 0.5 & JFC & 3 & EPS & 15 & 4 \\
HFC & Aluminium & 0.5 & HFC & 3 & EPS & 15 & 4 \\
\hline \multicolumn{7}{c}{ Total } \\
\hline
\end{tabular}

\section{Experimental Procedure}

The static flexural test of the hybrid composite sandwich panel was conducted in accordance with the ASTM C 393-00 standard [38] which is a standard test method for the flexural properties of sandwich constructions. This test method covers the determination of the properties of the flat sandwich constructions subjected to a flatwise flexure in such manner that the applied moments produce a curvature of the sandwich facing planes. The load was applied at $1 / 3$ and $2 / 3$ of the span length. The four-point bending test is preferred as it has the advantage of uniform tensile or compressive stresses with zero shear which are produced over the area between the loading points, not just under the loading point as in the three-point bending test $[39,40]$. Thus, within the central section, more of the material is stressed to the same amount in four-point loading than in central loading and failure due to moments will begin at the weakest point [41]. The 
schematic illustration of the flexural test and the cross section view of the samples are given in Figure 1.

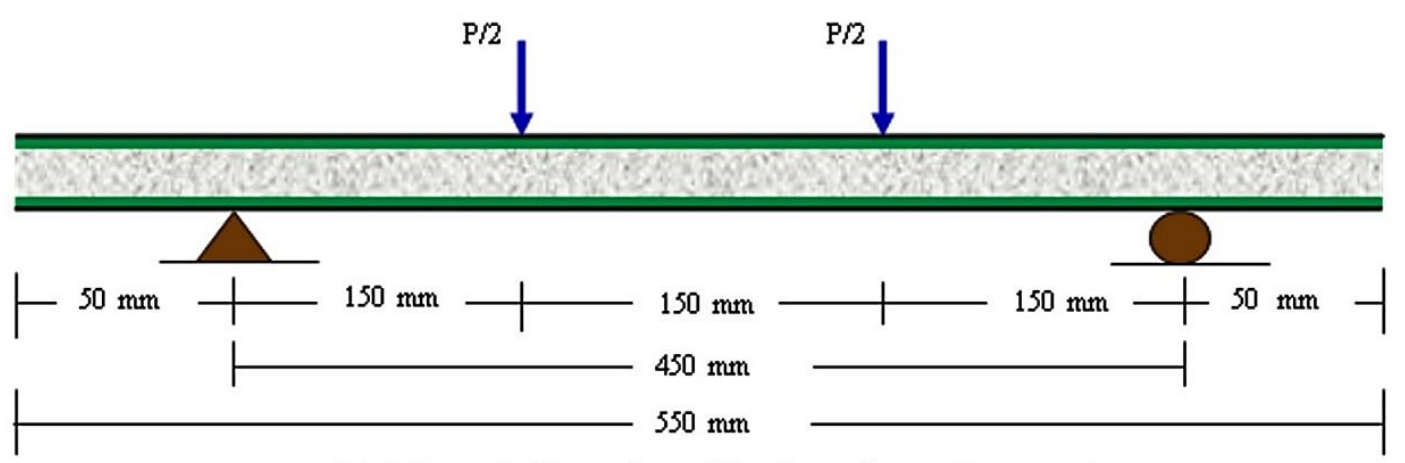

(A) Schematic illustration of the flexural test: Not to scale

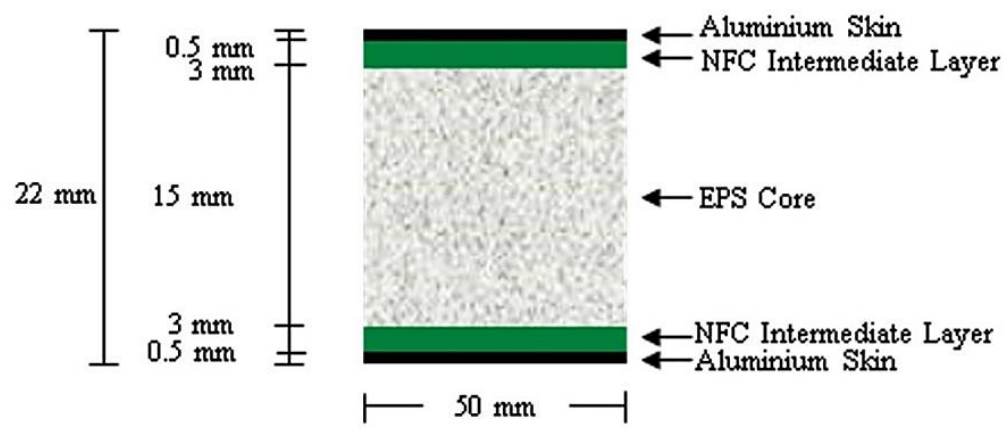

(B) Cross section of the samples: Not to scale

Figure 1. The schematic illustration of flexural test and cross section view of the sample.
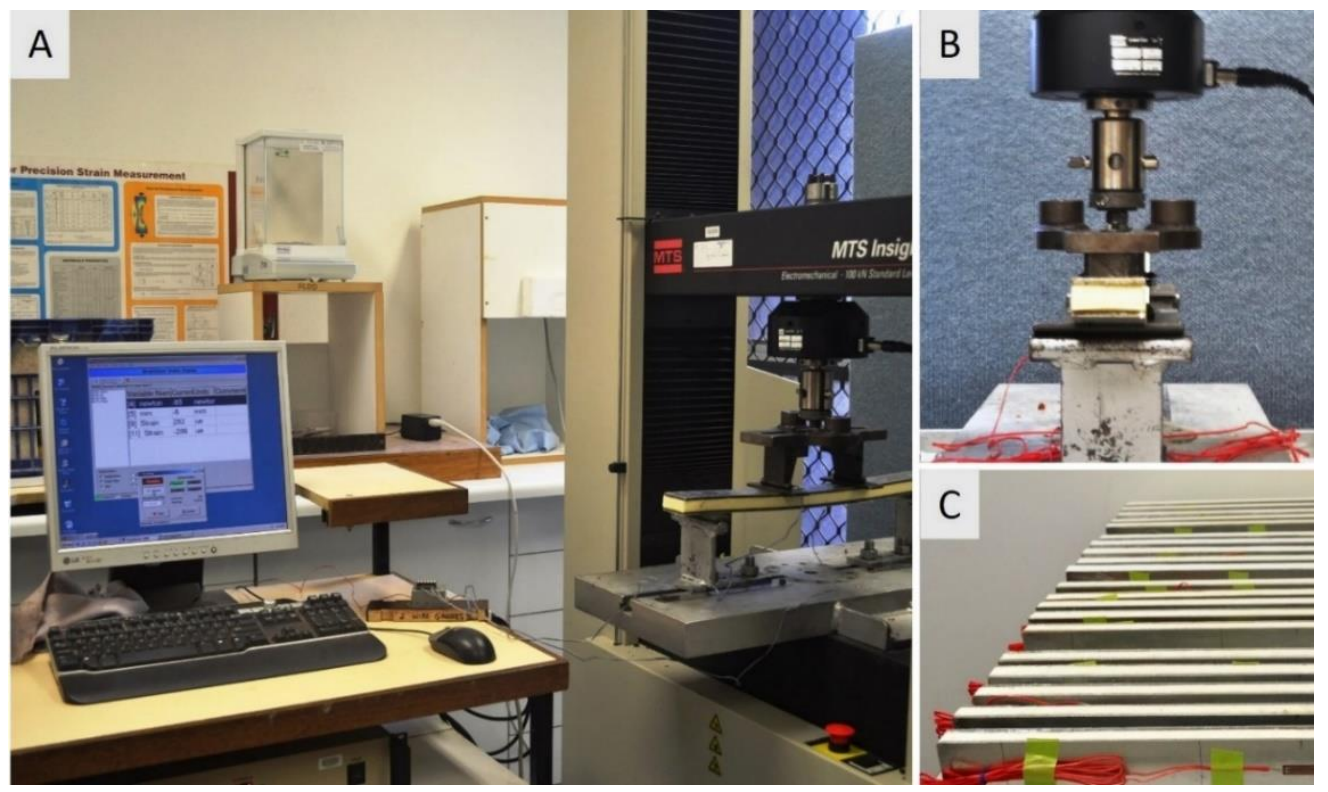

Figure 2. The actual set up of flexural test. (A) MTS testing machine connected to System 5000 data logger for strain and displacement recording, (B) Front view of the testing set-up, (C) Produced samples prior to be tested. 
The actual set up of the test is given in Figure 2. The testing was performed using a $100 \mathrm{kN}$ servo-hydraulic machine with a loading rate of $5 \mathrm{~mm} / \mathrm{min}$. The loading pins and the supports had a diameter of $20 \mathrm{~mm}$. In order to prevent the existence of early failure, a steel plate was placed between the specimen and loading point and also between the specimen and support. Strain gauges were attached at the bottom surface and the middle top of specimens for recording the longitudinal strain. The applied load, displacement and strains were obtained using a System 5000 data logger. Prior to each run of the testing, the loading pins were set up to nearly touch the top surface of the specimen and the machine then was re-set to the default position. The test was terminated after a visible collapse mechanism was encountered or the specimen was undergoing a large displacement but could not carry any increased load.

\section{RESULTS AND DISCUSSION}

\section{Comparison of Ultimate Load}

Figure 3 shows the average maximum load carrying capacity and deflection against the type of intermediate layer of the sandwich panels. The average ultimate load for sandwich panels with JFC and HFC intermediate layer was $396.55 \mathrm{~N}$ and $591.5 \mathrm{~N}$, respectively. On the other hand, the average ultimate load of sandwich panel without the intermediate layer was $305.75 \mathrm{~N}$. The results indicated that the load carrying capacity of the hybrid sandwich panel with JFC intermediate layer was $29.6 \%$ higher than that of the conventional sandwich panel and approximately $93.46 \%$ higher with HFC intermediate layer. The difference in load carrying capacity between the two hybrid sandwich panels was $49.27 \%$ in which the load carrying capacity of the hybrid sandwich panel with HFC intermediate layer was higher than those with JFC intermediate layer.

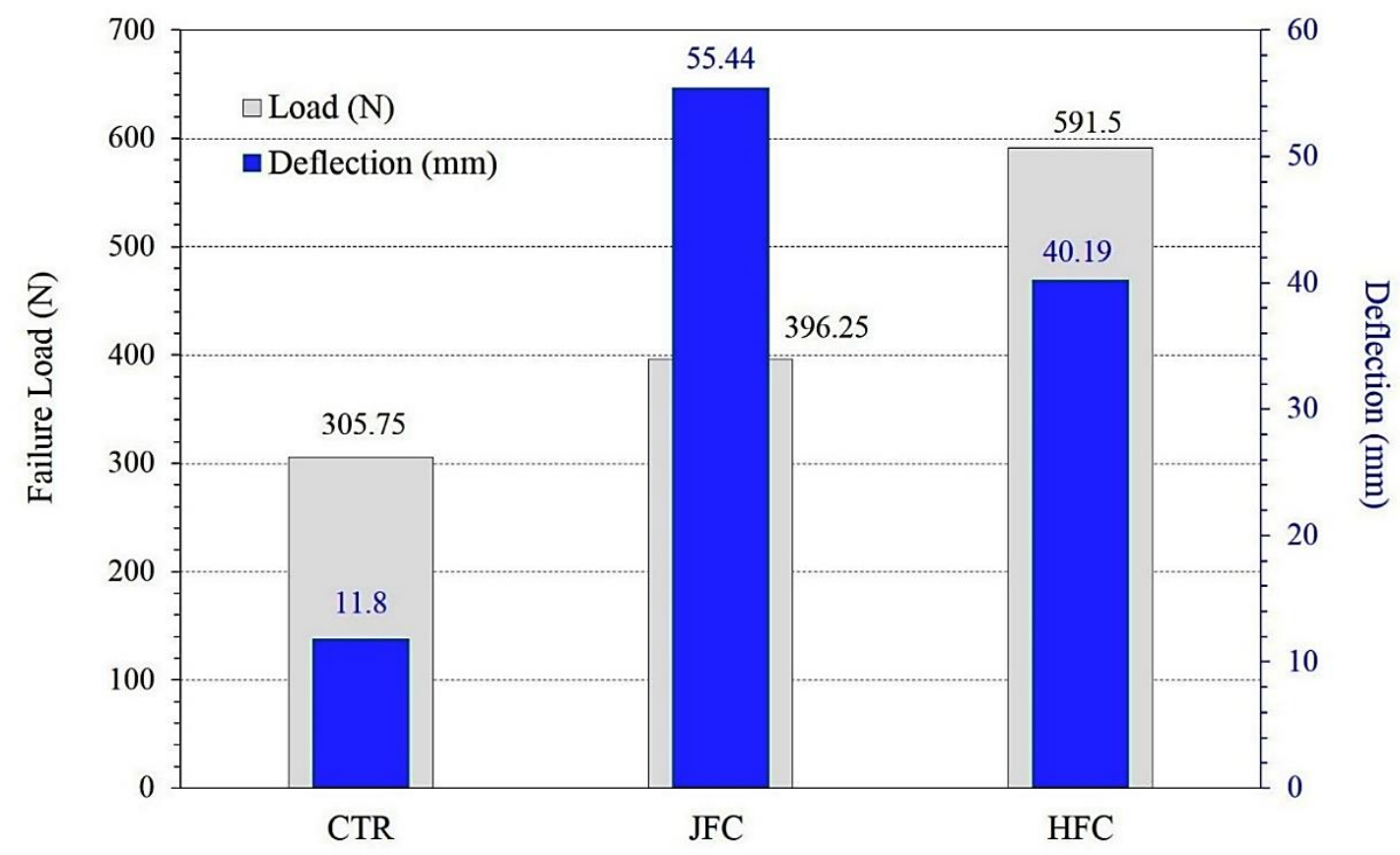

Type of Intermediate Layer (IL)

Figure 3. The average maximum load carrying capacity and deflection against the type of intermediate layer. 
It can also be observed from this figure that the sandwich panel without intermediate layer (CTR) and hybrid sandwich panel with the HFC intermediate layer had higher stiffness than the hybrid sandwich panel with the JFC intermediate layer. The JFC samples reached the maximum load with a large deflection, while HFC and CTR samples reached the corresponding values with a fairly small deflection. The results also confirmed the previous finding which stated that hybrid sandwich panel with intermediate layer was superior than an aluminium equivalent structure and sandwich panels that consisted of skins and core only [27]. The failure of sandwich panel can be caused by various mechanisms within the constituent materials $[2,42]$. If a low density foam core is used in a sandwich panel, it is very likely that they will fail either due to indentation or core shear [27]. Such mechanisms were clearly observed within the CTR specimens, especially the indentation failure. All hybrid sandwich panels collapsed under either shear core or delamination at the interface of the core and intermediate layer. It seemed that the existence of intermediate layer within the sandwich structure had prevented an early failure mechanism such as face wrinkling and indentation. Similar findings have been reported previously which stated that sandwich panels with a soft core were quite vulnerable to inwards wrinkling of the compression skin which resulted in a lower ultimate strength [43].

\section{Comparison of Load-deflection Behaviour}

For comparison purposes, one specimen from each category was selected for a representation of the load-deflection curve. A specimen labelled as CTR-SP-3 was chosen for the depiction of specimens in the CTR category while JFC-SP-1 and HFC-SP-1 were selected for the JFC and HFC category, respectively. It is very apparent in Figure 4 that the introduction of intermediate layer in sandwich panels, which are represented by JFC and HFC curves, has substantially enhanced the load carrying capacity of the sandwich panels. The load-deflection graph of CTR showed that the specimen had a typical ductile material. The curve did not show a distinct yield point prior to reaching failure, but then decreased sharply at the end of the plastic region due to a failure initiation in the specimens. It seemed that the failure occurred in a form of sudden cracking of the core due to shear propagation. The graphs consisted of an initial linear part followed by a non-linear portion. Likewise to the configuration of load-deflection curves for CTR specimen, the curve for JFC specimen also showed a typical true ductile behaviour in which there was no sharp drop in the load. The graph was initiated by a linear portion up to the load of approximately $150 \mathrm{~N}$, then deviated gradually until reaching the ultimate loads. After reaching the ultimate value, the load decreased gradually as the deflection increased until the testing was automatically terminated by the testing machine. In general, the sandwich panel with HFC intermediate layer demonstrated a ductile behaviour up to the ultimate load and then collapsed in a brittle manner. The graph departed with a linear portion, then gradually diverged until the ultimate load was reached. There was an abrupt drop in the load carrying capacity at the point of the ultimate load. Likewise to the previous two graphs, it was also difficult to distinguish a yield point. The graphs just deviated steadily from the departing point until reaching the ultimate load. It was assumed that there was a sudden crack at the core at the initial stage of failure mechanism, followed by delamination between the core and intermediate layer. Furthermore, the initial part of the three graph was quite linear which had arisen from the linear elastic deformation of the cell structures. In the sandwich with foam core, the slope of load-deflection curve will change as the cell began to rupture due to stretching and beyond that point, the foam almost uncontrollably deformed and finally collapsed at the maximum load [44]. 


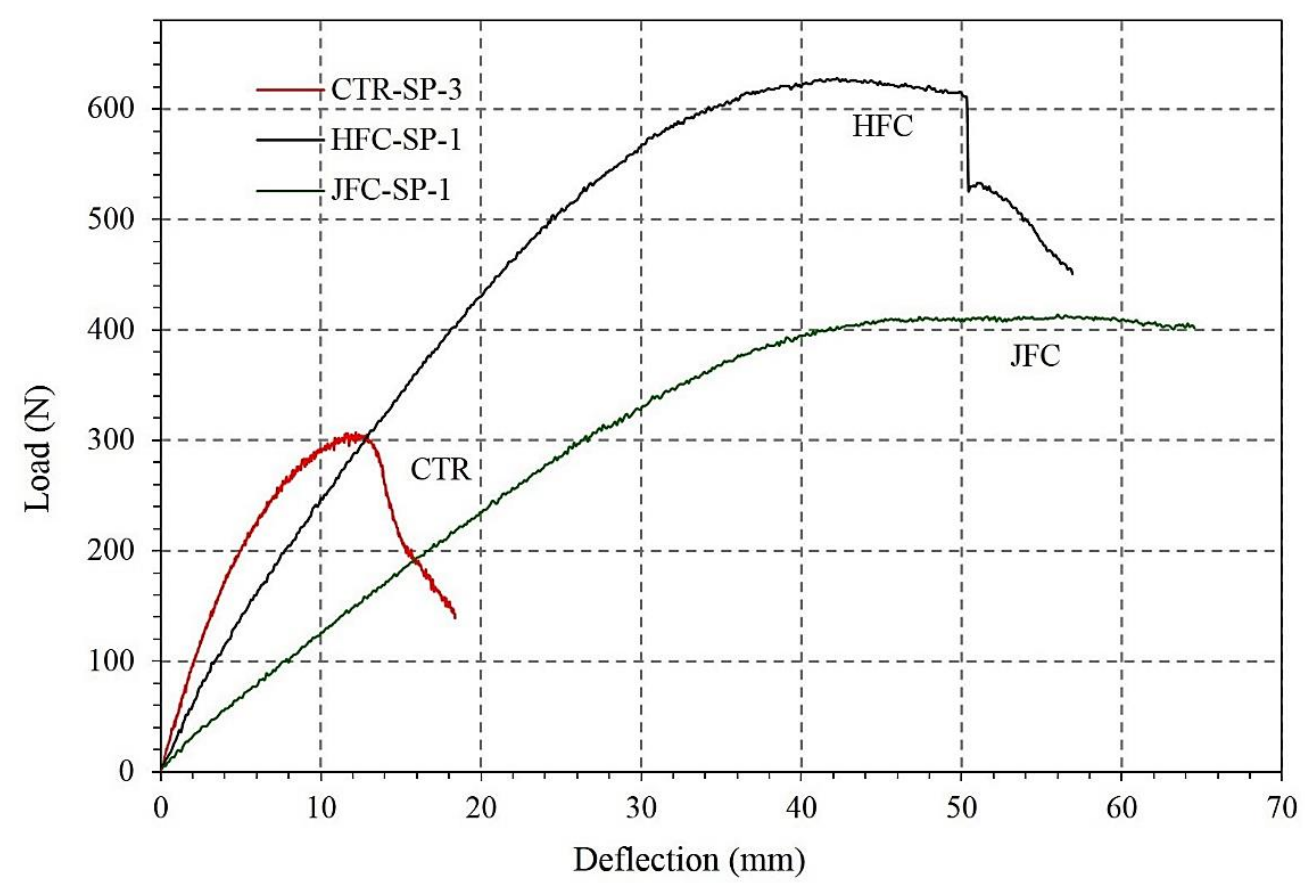

Figure 4. Load-deflection graphs of representative specimens for CTR, JFC and HFC groups.

It is also clearly seen in this figure that the introduction of intermediate layer had created more ductile sandwich panels compared to the conventional form of sandwich panels. Structures made from ductile material can avoid a catastrophic failure [45] and are more desirable for public infrastructures. The two hybrid sandwich panels with natural fiber composites intermediate layer had shown excellent strength and stiffness, though there had been some concerns about the stiffness of the hybrid sandwich panels with the JFC intermediate layer. Theoretically, the JFC specimens should be stiffer than CTR specimens. However, the existence of a debonding mechanism within JFC specimens had reduced the stiffness of the JFC hybrid panels. The early separation of the intermediate layer and the EPS core was resulted from the low bond strength of the two adjacent materials. Such failure mechanism was also reported previously for the sandwich structure with EPS and XPS foam core [26]. Furthermore, the theoretical concept of sandwich panel was developed based on the assumption that the cross-sections are plane and perpendicular to the longitudinal axis of the unloaded beam $[2,46]$. During the initial stage of the test, the CTR and HFC specimens remained plane and failed due to the initiation of shear cracking so that they followed the assumption made for the theoretical framework. Meanwhile, the JFC specimens did not follow this as the collapsed mechanism initiated was a debonding mechanism, such as reported in Reference [26], so that the cross section did not remain plane when bending took place. In short, it can be inferred that debonding mechanism is also an important aspect when further developing this new hybrid panel in the future. If the early debonding mechanism within JFC panels can be prevented, it must be stiffer than the panel without the intermediate layer. In addition, a sudden drop at the ultimate load for the hybrid sandwich panels with HFC intermediate layer is not desirable for an earthquake resistant structure. 


\section{Comparison of Load-strain Behaviour}

The typical load-strain relationship of the sandwich panels tested in this research is shown in Figure 5. The strain gauges were attached in the middle of the top and bottom surface of the sandwich panel beams to measure the longitudinal strain. As expected, the loadstrain curves presented a non-linear evolution of strain at the compression and tension side of the specimens. The load-strain evolution may be expected based on the behavior of the individual constituent materials comprising a sandwich structure [47]. The aluminium skin and EPS core used in this research were ductile in nature and typically respond in a non-linear fashion.

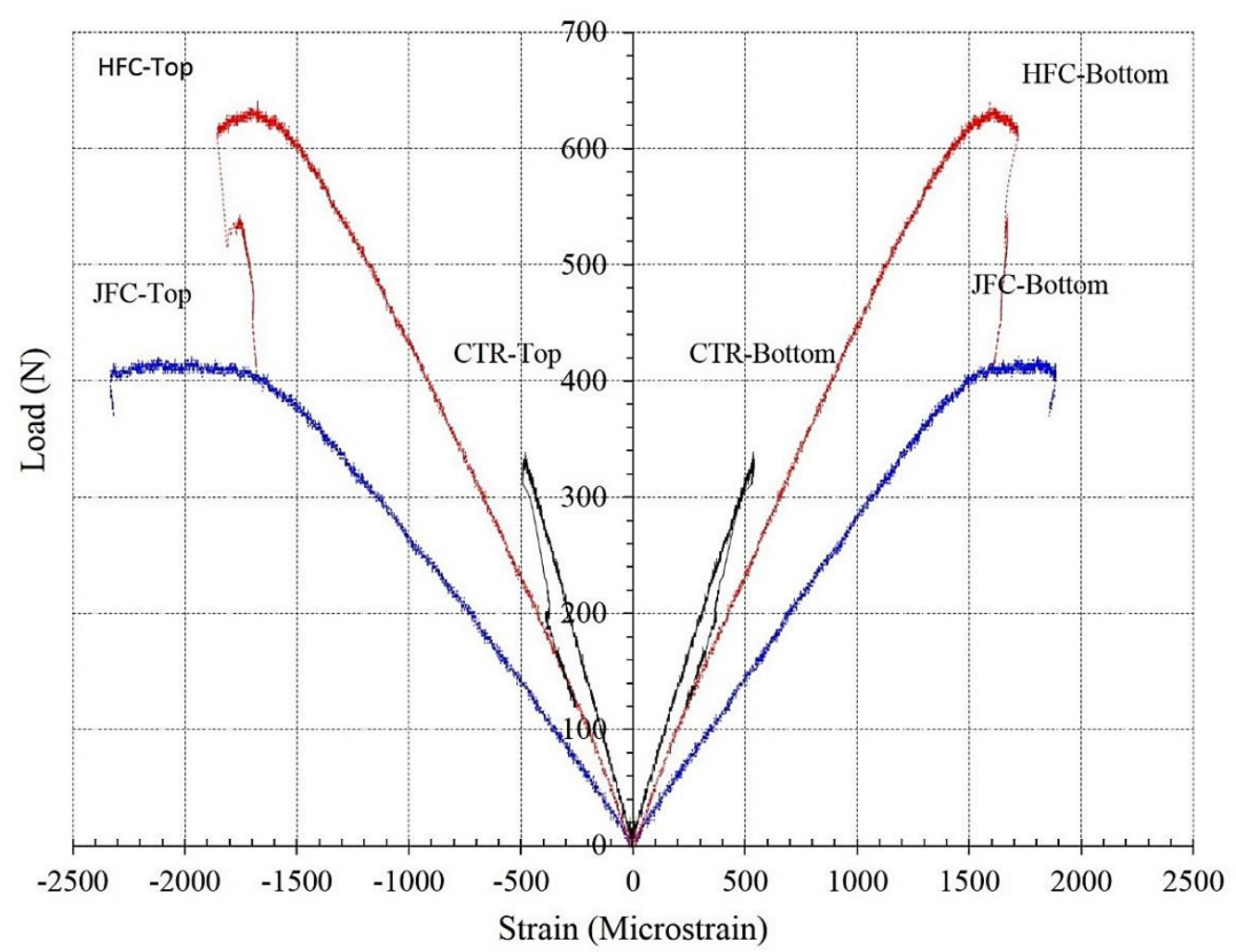

Figure 5. Comparison of load-strain relationship for the representative samples of CTR, JFC and HFC groups

It is clearly demonstrated in the figure that the recorded strain of hybrid sandwich panels with JFC and HFC intermediate layer are higher than the conventional sandwich panels (CTR). This meant that the deformation capability of the hybrid sandwich panel was notably higher than the conventional sandwich panel with the intermediate layer. The curve for each specimen category suggested that the longitudinal strains at the top (compression) and the bottom (tension) surfaces increased linearly with the load only at the very early region at the load, about $50 \mathrm{~N}$ to $100 \mathrm{~N}$. Beyond this particular point, both sides of the curves started to deviate differently until they reached their ultimate loads. This finding verified an experimental and finite element work reported previously which demonstrated that strain in the skins deviated from linearity after the initiation of the first failure mechanism and that these deviations were different for the two skins of a sandwich beam [48]. The curves for the hybrid sandwich panels showed better ductile behaviour in which no distinct yield point was observed prior to the point of the ultimate load. The 
curve for CTR specimen showed a linear elastic behaviour up to the load of approximately $80 \mathrm{~N}$ and started to initiate plastic region beyond this point. The strain at this point was almost comparable for both compression and tension sides, which was approximately 100 microstrains. The specimen failed at a load of around $330 \mathrm{~N}$ corresponding to a compression strain of 480 microstrains and 540 microstrains for the tension side. This meant that the skin behaved slightly stiffer in compression than in tension. As discussed earlier, the CTR specimen failed at only 480 microstrains in the compression side. This value was only about $20 \%$ of the compression strain of JFC specimen (2350 microstrains) and $26 \%$ of strain at the HFC specimen (1850 microstrains). This also indicated that for the conventional sandwich panel (CTR), the aluminium skin was not optimally utilized due to the prematurely failure of the sandwich panel under shear or skin buckling. The CTR specimen collapsed at an applied load of $330 \mathrm{~N}$ which corresponded to a facing stress of $41.2 \mathrm{MPa}$, which was significantly lower than the yield tensile strength of Aluminium $5005 \mathrm{H} 34$ (138 MPa). There was also evidence that the strain at the skin of the CTR specimen decreased in a significant amount after reaching the peak load. The strain of CTR decreased to 260 microstrains for the compression side and 240 microstrains for the tension side after reaching its peak load.

The JFC specimen failed at a load of around $420 \mathrm{~N}$ or a facing stress of $46.68 \mathrm{MPa}$ corresponding to the 1900 microstrains at the tension side and 2350 microstrains at the compression side, which meant that the skin behaved reasonably stiffer in the tension side than in compression. The large difference of strain at the tension and compression side also indicated that after a certain load, approximately at $250 \mathrm{~N}$, the beam did not follow the theoretical assumption $[2,46]$, where the beam sections should remain plane during the flexural loading. Furthermore, the incomparable strains at both sides of the JFC specimen suggested that there was something happening along the longitudinal axis of the specimen which was most likely a delamination process at the interface of the adjacent constituent materials due to the loss of bonding strength. Such mechanism had allowed the compression side to deform larger than at the tension side. This phenomenon explained clearly why the load carrying capacity of the JFC sample was substantially lower than the HFC specimen. The curve for JFC specimen was linear at the initial portion up to the load of about $100 \mathrm{~N}$ and started to move away, forming a non-linearity beyond this point. The strain at this point was 300 microstrains for the tension and 350 microstrains for the compression side. Unlike the two previous sample categories, the representative specimen for HFC group failed at almost a comparable strain for both compression and tension, which was 1750 microstrains for the bottom surface (tension), and 1850 microstrains for the top surface (compression) side. These strains corresponded to the load of approximately $640 \mathrm{~N}$ or a facing stress of $65.9 \mathrm{MPa}$. The curve also showed an initial linear portion of up to the load at $100 \mathrm{~N}$, in which the curve started to deviate, forming a plastic region.

Considering the typical failure for the conventional sandwich panel which was a shear failure of the core as commonly observed for the sandwich structure [2, 42], the behaviour can be explained that once the failure occurred within the specimen, the aluminium skins tried to return to its original length as the deformation was still in the range of its elastic region but the strains never returned to zero. This situation was actually not caused by a permanent set already established within the aluminium skin. It was most likely that the trace of EPS core prevented the beam from returning to its original shape. The maximum facing strength of all tested specimens never exceeded the yield tensile strength of the aluminium skins. A similar situation was also clearly noticed in the hybrid sandwich panel where the strains also never returned to zero. In the case of the hybrid 
sandwich panel, however, such condition was not only affected by the trace of the EPS core but also due to a permanent set already established within the intermediate layers. The maximum recorded ultimate load of JFC and HFC specimens was $420 \mathrm{~N}$ and $640 \mathrm{~N}$, respectively. These ultimate loads were comparable to a facing stress of $46.68 \mathrm{MPa}$ for JFC and 65.87 MPa for HFC. Based on the coupon test of the two intermediate layers, the maximum tensile strength of JFC and HFC was $42.44 \mathrm{MPa}$ and $31.37 \mathrm{MPa}$, respectively. It was noticeably observed that the maximum strength at the outermost part of the sandwich structure exceeded the yield tensile strength of the intermediate layer. This meant that both intermediate layers had already stretched beyond their linear elastic capacity and a permanent set had already been established. The stress evolution in the alumnium skin was possibly still within its linear capacity and might return to its original shape, but as the skins were perfectly bonded to the intermediate layer, the recorded strains never returned to zero. Overall, the higher deformation capability of hybrid sandwich panels shown by their load-strain curves was attributed to the presence of intermediate layer, which prevented the compression buckling or wrinkling of the aluminium skins as indicated by a previous reported research [27].

\section{Comparison of failure mode}

Figure 6 (A) shows the typical failure modes of the conventional panels (CTR). There were two types of failure mechanism that were observed for CTR specimens. The first was a shear failure of the core that began as a debonding at the interface of the skin and core near the loading point towards the edge. At the point where the bond strength of the skin-core was higher than the shear strength of the core, the core shear failure started as individual cracks tilted at about $45^{\circ}$ to the neutral axis. More dispersed cracks diagonally appeared towards the bottom part as the loading increased. With the continued loading, the cracks propagated continuously along the bottom part and terminated at the roller. Such failure mechanisms were also reported previously [39]. The second was an indentation failure of the specimen around the loading point. Two rectangular plates were placed between the loading point and the top surface of the specimens to avoid early indentation failure. However, it was difficult to reach a perfectly balanced position of the loading roller at the plate, resulting in an unbalanced loading transferred from the plate to the specimen. This observed fact triggered an indentation failure at the top surface of the specimen at the edge of the plate. Indentation began with the deformation of the skin which followed the plate's edge profile. It seemed that the use of a thin aluminium skin with the thickness of only $0.5 \mathrm{~mm}$ had triggered this type of failure mechanism. In the case of the sandwich beam, indentation failure commonly occurs under the loading point where significant local deformation takes places of the loaded skins into the core, resulting in high local stress concentrations [42].

The failure of hybrid sandwich panels with the JFC intermediate layer is shown in Figure 6 (B). It can be observed that the debonding at the interface of the intermediate layer-core was the only observed failure mode for this sample category and accordingly, the load-deflection curves for this sample category were similar. The failure mechanism might be explained as follows. As the flexural loads were applied and increased continuously, the bottom part of the specimen stretched and conversely, the upper part compressed. Accordingly, the foam core behaved in the same manner as the deflection increased gradually. It was most likely that the debonding mechanism began when the compression stress at the upper intermediate layer and core interface exceeded its bond strength. The figure also clearly shows that there was no trace of EPS foam on the 
debonded interface, indicating poor bond strength between the core and the intermediate layer.
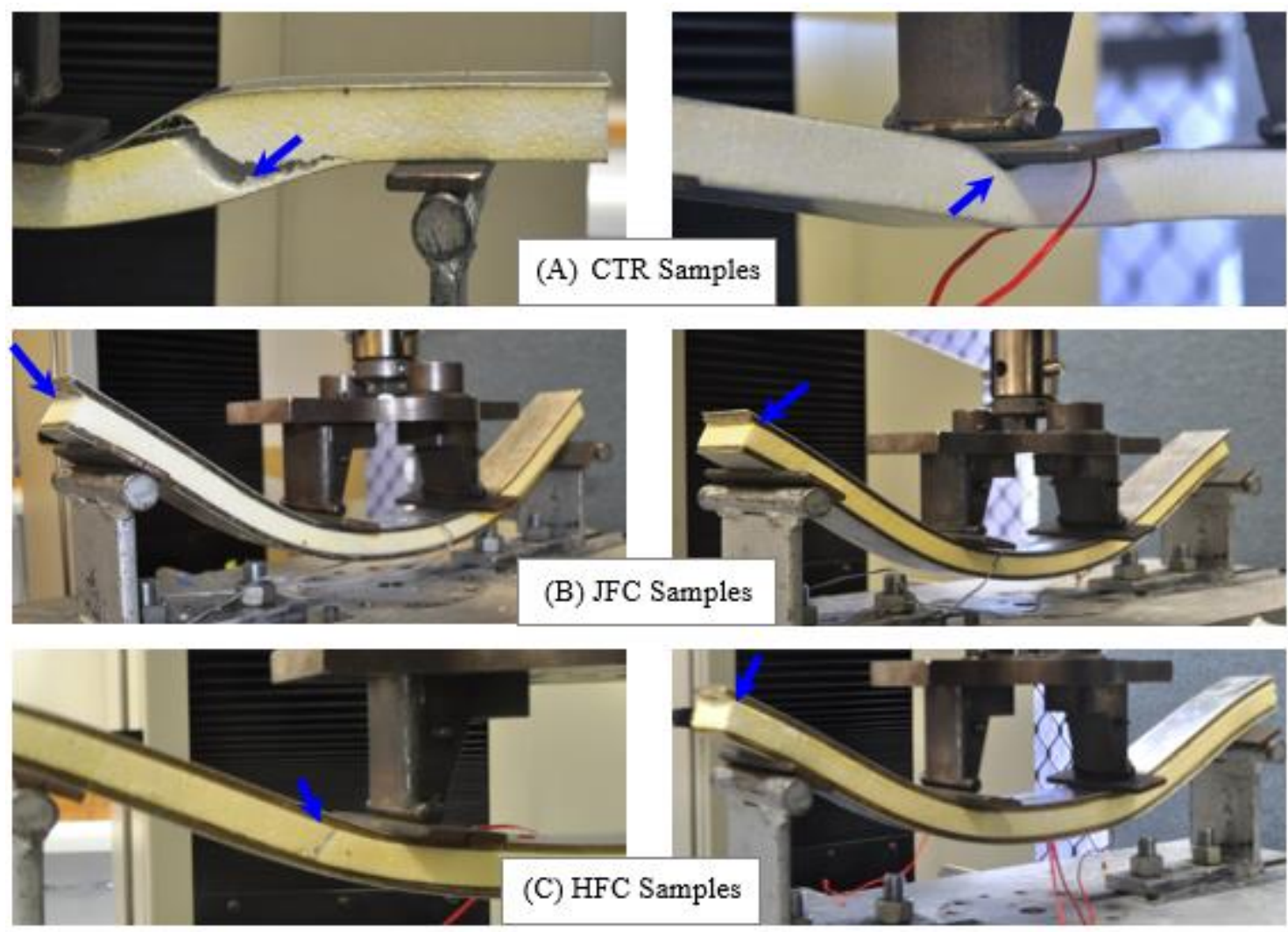

Figure 6. Failure mechanisms of (A) CTR samples, (B) JFC samples, and (C) HFC samples

There were two different types of failure mechanisms for hybrid sandwich panels with the HFC intermediate layer; debonding of the core-intermediate layer and shear failure of the core. Similar to the shear failure of the conventional sandwich panels, the failure mechanism began with a minor crack near the edge of the plate under the loading point. The cracks then propagated towards the bottom intermediate layer at an angle of approximately $45^{0}$ to the longitudinal axis. As the load increased, the bottom end of the diagonal cracks became larger, triggering a delamination between the core and intermediate layer. It seemed that the core's shear failure would take place if the bond at the interface of the core-intermediate layer had an adequate strength to sustain more loads. Meanwhile, debonding or delamination mechanism was established if the bond strength was reasonably lower. The failure modes for hybrid sandwich panels with HFC intermediate layer are shown in Figure 6 (C). All failure mechanisms observed in this experimental work were similar to a previous study reported by Gdoutos and Daniel [49]. It was also clearly demonstrated that the core shear failure existed in both conventional and hybrid sandwich panel. This confirmed the previous finding which stated that core failure due to shear is a common failure mode in a sandwich structure [2, 42].

\section{CONCLUSIONS}

The results of the experimental investigation demonstrated that hybrid sandwich panel exhibited a superior performance compared to the conventional sandwich panels. The 
intermediate layer contributed significantly to enhancing the load carrying capacity of the hybrid sandwich panel developed in this study. More specific findings are outlined as follows.

i). The load carrying capacity of hybrid sandwich panel with JFC intermediate layer was $29.60 \%$ higher than the conventional sandwich panel and correspondingly 93.46\% higher for the sandwich panel with HFC intermediate layer. Also, hybrid sandwich panels developed a much larger area under the load-deflection curve than those of the conventional sandwich panels, indicating their greater toughness.

ii). The introduction of intermediate layer helped the hybrid sandwich panels to sustain larger strain prior to reaching their ultimate loads, resulting in higher deformation capability than the conventional sandwich panel. The intermediate layer also prevented the sandwich panel to prematurely fail under buckling or indentation.

iii). Indentation and core shear were observed as the failure mode of the conventional sandwich panel. Meanwhile, core failure due to shear and delamination at the interface of the intermediate layer and the core were identified as the failure modes of the hybrid sandwich panel.

\section{ACKNOWLEDGEMENTS}

The authors would like to greatly appreciate the sponsorship from the Government of Indonesia through DGHE Project and The University of Mataram, which made this research possible. Also, the authors would like to acknowledge The Centre of Excellence in Engineered Fibre Composites (CEEFC) and School of Civil Engineering and Surveying Faculty of Health, Engineering and Sciences, University of Southern Queensland for providing access to laboratory facilities. We would also like to say our warmest thanks to the technicians, Wayne Crowell and Mohan Trada, for their help and assistance during the experimental works.

\section{REFERENCES}

[1] Davies JM. Lightweight sandwich construction. London: Blackwell science; 2011.

[2] Zenkert D. An introduction to sandwich construction. Solihull: EMAS; 1995.

[3] Zhou D, Stronge W. Mechanical properties of fibrous core sandwich panels. International Journal of Mechanical Sciences. 2005;47:775-98.

[4] Schwarts-Givli H, Rabinovitch O, Frostig Y. High-order nonlinear contact effects in cyclic loading of delaminated sandwich panels. Composites Part B: Engineering. 2007;38:86-101.

[5] Moreira R, Rodrigues JD. Static and dynamic analysis of soft core sandwich panels with through-thickness deformation. Composite Structuctures. 2010;92:201-15.

[6] Maleque MA, Radhi M, Rahman MM. Wear study of Mg-SiCp reinforcement aluminium metal matrix composite. Journal of Mechanical Engineering and Sciences. 2016;10:1758-64.

[7] Kasim AN, Selamat MZ, Daud MAM, Yaakob MY, Putra A, Sivakumar D. Mechanical properties of polypropylene composites reinforced with alkaline treated pineapple leaf fibre from Josapine cultivar. International Journal of Automotive and Mechanical Engineering. 2016;13:3157-67. 
[8] Fahmi I, Abdul Majid MS, Afendi M, Helmi EA, M. Haameem JA. Low-velocity impact responses of Napier fibre/polyester composites. International Journal of Automotive and Mechanical Engineering. 2016;13:3226-37.

[9] Icardi U, Ferrero L. Optimisation of sandwich panels with functionally graded core and faces. Compos Sci Technol. 2009;69:575-85.

[10] Rocca S, Nanni A. Mechanical characterization of sandwich structure comprised of glass fiber reinforced core: Part 1. Composites in Construction: Third International Conference. France. 2005. p. 11-3.

[11] Benayoune A, Samad AAA, Trikha D, Ali AAA, Ashrabov A. Structural behaviour of eccentrically loaded precast sandwich panels. Construction Building Materials. 2006;20:713-24.

[12] Rejab M, Cantwell W. The mechanical behaviour of corrugated-core sandwich panels. Composites Part B: Engineering. 2013;47:267-77.

[13] Rejab M, Ushijima K, Cantwell W. The shear response of lightweight corrugated core structures. Journal of Composite Materials. 2014;48:3785-98.

[14] Russo A, Zuccarello B. Experimental and numerical evaluation of the mechanical behaviour of GFRP sandwich panels. Composite Structuctures. 2007;81:575-86.

[15] Van Erp G, Rogers D. A highly sustainable fibre composite building panel. Proceedings of the international workshop on fibre composites in civil infrastructure-past, present and future. USQ, Australia. 2008. p. 1-2.

[16] Fan H, Meng F, Yang W. Sandwich panels with Kagome lattice cores reinforced by carbon fibers. Composite Structuctures. 2007;81:533-9.

[17] Masters I, Evans K. Models for the elastic deformation of honeycombs. Composite Structuctures. 1996;35:403-22.

[18] Meraghni F, Desrumaux F, Benzeggagh M. Mechanical behaviour of cellular core for structural sandwich panels. Composites Part A: Applied Science and Manufacturing. 1999;30:767-79.

[19] Khan M. Compressive and lamination strength of honeycomb sandwich panels with strain energy calculation from ASTM standards. Proceedings of the Institution of Mechanical Engineers, Part G: Journal of Aerospace Engineering. 2006;220:375-86.

[20] Baral N, Cartié DD, Partridge IK, Baley C, Davies P. Improved impact performance of marine sandwich panels using through-thickness reinforcement: experimental results. Composites Part B: Engineering. 2010;41:117-23.

[21] Liu Q, Zhao Y. Effect of soft honeycomb core on flexural vibration of sandwich panel using low order and high order shear deformation models. Journal of Sandwich Structures and Materials. 2007;9:95-108.

[22] Ismail AE, Che Abdul Aziz MA. Tensile strength of woven yarn kenaf fiber reinforced polyester composites. Journal of Mechanical Engineering and Sciences. 2015;9:1695-704.

[23] Asif Iqbal AKM, Arai Y. Study on Low-Cycle Fatigue Behavior of Cast Hybrid Metal Matrix Composites. International Journal of Automotive and Mechanical Engineering. 2015;11:2504-14.

[24] Taufik RS, Adibah M NF, Muhamad MR, Hasib H. Feasibility Study of Natural Fiber Composite Material for Engineering Application. Journal of Mechanical Engineering and Sciences. 2014;6:940-8.

[25] Jiang D, Shu D. Local displacement of core in two-layer sandwich composite structures subjected to low velocity impact. Compos Struct. 2005;71:53-60. 
[26] Kim J, You Y-C. Composite behavior of a novel insulated concrete sandwich wall panel reinforced with GFRP shear grids: Effects of insulation types. Materials. 2015;8:899-913.

[27] Mamalis A, Spentzas K, Pantelelis N, Manolakos D, Ioannidis M. A new hybrid concept for sandwich structures. Composite Structuctures. 2008;83:335-40.

[28] Roslan S, Hassan M, Rasid Z, Zaki S, Daud Y, Aziz S, et al. Mechanical properties of bamboo reinforced epoxy sandwich structure composites. International Journal of Automotive and Mechanical Engineering. 2015;12:2882-92.

[29] Adebisi AA, Maleque MA, Rahman MM. Metal Matrix Composite Brake Rotor: Historical Development and Product Life Cycle Analysis. International Journal of Automotive and Mechanical Engineering. 2011; 4:471-80.

[30] Bank LC. Composites for construction: structural design with FRP materials: John Wiley \& Sons; 2006.

[31] Sapuan S, Bachtiar D, Hamdan M. Flexural properties of alkaline treated sugar palm fibre reinforced epoxy composites. International Journal of Automotive and Mechanical Engineering. 2010;1:79-90.

[32] Ibrahim M, Sapuan S, Faieza A. Mechanical and Thermal Properties of Composites From Unsaturated Polyester Filled With Oil Palm Ash. Journal of Mechanical Engineering and Sciences. 2012;2:133-47.

[33] Salleh Z, Yusop M, Rosdi M. Mechanical properties of activated carbon (AC) coir fibers reinforced with epoxy resin. Journal of Mechanical Engineering and Sciences. 2013;5:631-8.

[34] Ismail AE, Aziz MCA. Tensile strength of woven yarn kenaf fiber reinforced polyester composites. Journal of Mechanical Engineering and Sciences. 2015;9:1695-704.

[35] Fajrin J. Alternative Theoretical Frameworks for Hybrid Sandwich Panel with Intermediate Layer. Jurnal Rekayasa Sipil. 2015;11:1-11.

[36] Fajrin J, Zhuge Y, Bullen F, Wang H. Significance analysis of flexural behaviour of hybrid sandwich panels. Open Journal of Civil Engineering. 2013;3:1-7.

[37] Fajrin J. The Application of Statistical Design of Experiments to Study the InPlane Shear Behaviour of Hybrid Composite Sandwich Panel. Civil Engineering Dimension. 2016;18:25-30.

[38] Standard A. C393-00. Standard Test Method for Flexural Properties of Sandwich Constructions. ASTM C393. 2000.

[39] Harte A-M, Fleck NA, Ashby MF. Sandwich panel design using aluminum alloy foam. Advanced Engineering Materials. 2000;2:219-22.

[40] Baker AAB. Composite materials for aircraft structures: Virginia: Education Series; 2004.

[41] Kuenzi EW. Flexure of structural sandwich construction. Wisconsin, USA.: United States Department of Agriculture, Forest Products Laboratory; 1958.

[42] Daniel I. Influence of core properties on the failure of composite sandwich beams. Journal of Mechanics of Materials and Structures. 2009;4:1271-86.

[43] Sharaf T, Shawkat W, Fam A. Structural performance of sandwich wall panels with different foam core densities in one-way bending. J Compos Mater. 2010;44:2249-63.

[44] Mirzapour A, Beheshty MH, Vafayan M. The response of sandwich panels with rigid polyurethane foam cores under flexural loading. Iranian Polymer Journal. 2005;14:1082-8.

[45] Somayaji S. Civil engineering materials. New Jersey: Prentice Hall; 1995. 
[46] Deshpande V. The design of sandwich panels with foam core. Lecture Notes, Cambridge University, Cambridge, UK. 2002.

[47] Tuwair H, Volz J, ElGawady MA, Mohamed M, Chandrashekhara K, Birman V. Testing and evaluation of polyurethane-based GFRP sandwich bridge deck panels with polyurethane foam core. Journal of Bridge Engineering. 2015;21:04015033.

[48] Daniel IM, Abot JL. Fabrication, testing and analysis of composite sandwich beams. Composites Science and Technology. 2000;60:2455-63.

[49] Gdoutos E, Daniel I. Failure modes of composite sandwich beams. Journal of Theoretical Application Mechanics. 2008;35:105-18. 